\title{
Wind Tunnel Test of Wind Loads and Current Loads Acting on FLBT and LNG Bunkering Shuttles in Side-by-side Configuration and Comparison with Empirical Formula
}

\author{
Byeongwon Park*, Jae-Hwan Jung*, Sung-Chul Hwang*, \\ Seok-Kyu Cho", Dongho Jung ${ }^{*}$ and Hong Gun Sung \\ "Korea Research Institute of Ships and Ocean Engineering, Daejon, Korea \\ 병렬 배치된 FLBT 및 LNG-BS에 작용하는 \\ 풍하중 및 조류하중에 대한 풍동 시험 및 경험식 비교 연구

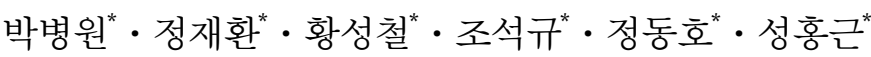 \\ "한국해양과학기술원 부설 선박해양플랜트연구소
}

KEY WORDS: Floating LNG bunkering terminal(FLBT) 해상부유식 LNG 벙커링 터미널, LNG bunkering LNG 벙커링, Wind tunnel test 풍동 시험, Shielding effect 차폐효과, Side-by-side mooring 병렬계류, Wnd load coefficient 풍하중 계수

\begin{abstract}
In recent years, LNG bunkering terminals are needed to supply LNG as fuel to meet the emission requirements of the International Maritime Organization (IMO). A floating LNG bunkering terminal (FLBT) is one of the most cost-effective and environmentally friendly LNG bunkering systems for storing LNG and transferring it directly to an LNG fuel vessel. The FLBT maintains its position using mooring systems such as spread mooring and turret mooring. The loads on the vessel and mooring lines must be carefully determined to maintain their positions within the operable area. In this study, the wind loads acting in several side-by-side arrangements on the FLBT and LNG-BS were estimated using wind tunnel tests in the Force Technology, and the shielding effect due to the presence of ships upstream was evaluated. In addition, the empirical formulations proposed by Fujiwara et al. (2012) were used to estimate the wind force coefficients acting on the FLBT and those results were compared with experimental results.
\end{abstract}

\section{1. 서 론}

친환경 에너지에 대한 관심의 증가로 $\mathrm{LNG(Liquefied} \mathrm{natural}$ gas)를 선박의 연로로 사용하는 방법에 대한 연구 개발이 활발 하게 진행되고 있다. 이와 더불어 국제해사기구(International Maritime Organization, IMO)에서는 유해배출가스에 대한 규제 강화의 움직임을 보이고 있어 유해배출가스가 적은 친환경 에 너지원에 대한 관심이 증가하고 있다.

연안에 설치된 FLBT(Floating LNG bunkering terminal)은 LNG 를 저장하고 있다가 $\mathrm{LNG}$ 를 연료로 사용하는 선박에 직접 공급 하는 시스템으로 비 인가자의 접근 제한, 폭발 등에 의한 피해 범위 축소, 이 수송 경로의 단순화 등의 장점을 지니고 있다.

FLBT는 특정 위치에 설치되며 운영하므로 이를 일정한 위치
에 고정시킬 수 있는 설비를 필요로 한다. 본 연구에서 대상으 로 하는 FLBT는 터렛 계류시스템으로 위치를 고정하고 있으며 환경 외력에 의한 영향이 최소화되는 방향으로 선수각을 조절 하는 Weathervaning이 가능하다. FLBT에 작용하는 환경 외력으 로는 크게 파도에 의한 힘, 바람에 의한 힘, 조류에 의한 힘으로 나눌 수 있으며 파도에 의한 힘은 포텐셜 이론을 기반으로 한 운동 해석 프로그램을 이용하여 추정할 수 있으며 이를 바탕으 로 계류 시스템에 대한 설계가 이뤄졌다(Song et al., 2016).

병렬 계류 또는 텐덤 계류 형태로 구성되어 있는 부유체에 대 한 풍하중 및 조류하중에 대한 실험 및 이론 연구가 진행되었다. Wnek et al.(2015)는 LNG shuttle tanker와 LNG platform barge가 병렬 계류되어 있는 상태에서의 풍하중에 대한 실험 연구를 수행 하였다. LNG platform barge 대비 LNG shuttle tanker의 상대 거리

Received 7 June 2017, revised 7 July 2017, accepted 11 August 2017

Corresponding author Seok-Kyu Cho: +82-042-866-3933, skcho33@kriso.re.kr

(C) 2017, The Korean Society of Ocean Engineers

This is an open access article distributed under the terms of the creative commons attribution non-commercial license (http://creativecommons.org/licenses/by-nc/3.0) which permits unrestricted non-commercial use, distribution, and reproduction in any medium, provided the original work is properly cited. 
및 선수각 변화에 따른 풍하중 실험 결과를 검토하였고, $\mathrm{LNG}$ shuttle tanker에 의한 차폐효과로 인해 폭방향으로 바람이 작용할 때 LNG platform barge 에 작용하는 횡력(Lateral force)이 감소하 는 것을 확인하였다. Fujiwara et al.(2012)는 다양한 실험 결과를 바탕으로 병렬 계류 되어 있는 LNGC(LNG carrier)에 작용하는 풍하중에 대한 경험식을 제시하였다. 다양한 형태의 병렬 계류 배치 조건의 풍동 시험 결과를 이용하여 구조물에 작용하는 풍하 중의 성분을 분리하였고, 이를 바탕으로 길이방향, 폭방향, 수직 방향 등의 풍하중을 추정하였다. 또한 LNGC가 LNG Platform의 하류에 위치하는 경우 차폐영역(Shieling area)의 영향을 고려하여 $\mathrm{LNGC}$ 에 작용하는 풍하중을 경험식을 통해 추정하였다.

본 연구에서는 FLBT에 작용하는 풍하중 및 조류하중을 추정 하기 위해 풍동에서 모형선을 이용한 실험을 덴마크 코펜하겐 소 재의 Force Technology에서 수행하였으며 계측 결과를 바탕으로 하중 계수를 추정하였다. 또한 FLBT와 LNG-BS(LNG bunkering shuttle)의 다양한 배치 경우를 통해 바람 또는 조류가 불어오는 방향에 선박이 위치할 때 발생하는 차폐효과(Shielding effect)를 검토하였으며 Fujiwara et al.(2012)가 제시한 경험식에 의한 풍하 중 추정 결과와 풍동 시험 결과를 비교하였다.

\section{2. 풍동 시험 평가조건}

\section{1 풍동 시험 대상 선박}

본 연구에서 대상으로 하는 FLBT는 LNG-BS의 기본 배치는 Fig. 1 과 같으며 각 제원을 Table 1에 정리하였다. 풍동 시험에 서는 실제 선박을 특정 비율로 축소한 모형을 사용하며 본 연 구에서는 1:250의 스케일을 적용하였다.

풍동 시험을 위해 제작된 모형선을 Fig. 2에 나타내었으며 4-body 병렬 배치 상태로 수행된 풍하중 계측 시험 장면을 Fig. 3에 표시하였다. 모형선의 재질은 고밀도 폴리우레탄 폼(High density polyurethane foam)으로 제작되었으며 대상 선박의 수선 면을 기준으로 하부와 상부가 분리되도록 하였다. 또한 상부 구

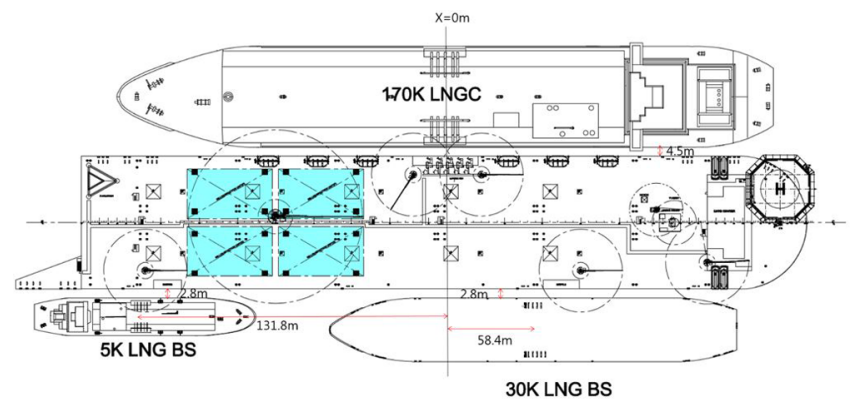

Fig. 1 Configuration of FLBT and LNG bunkering shuttles

Table 1 Main particulars of FLBT and LNG-BS

\begin{tabular}{ccccc}
\hline \hline & FLBT & 170k LNGC & 30k Shuttle & 5k shuttle \\
\hline Loa [m] & 355.0 & 294.0 & 172.0 & 99.0 \\
Beam [m] & 60.0 & 45.5 & 26.5 & 17.0 \\
Draft [m] & 13.5 & 11.95 & 5.08 & 4.3 \\
L/C & & Full & Ballast & Ballast \\
\hline
\end{tabular}

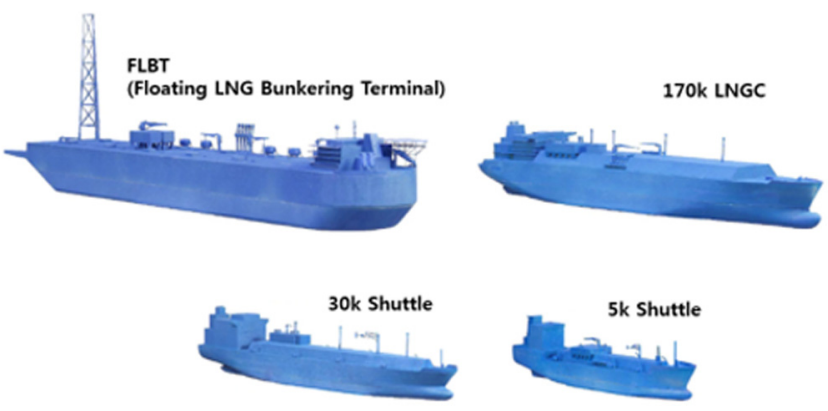

Fig. 2 Models for wind tunnel tests
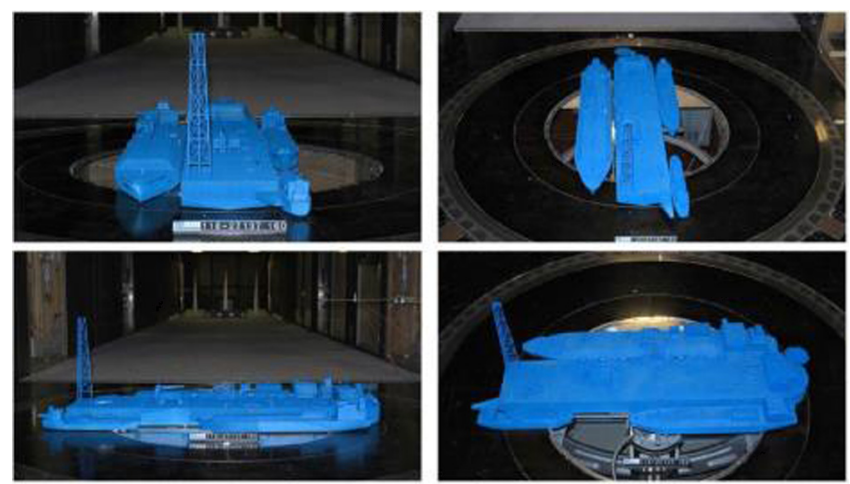

Fig. 3 Wind load test for 4-body side-by-side configuration

조물은 설계에 따라 스케일에 맞게 제작되었고, 일부 구조물은 통합된 형태로 간략화 하였다. 모형선의 표면은 충분한 거칠기 를 가지고 표면 마찰에 의한 박리점 및 마찰 저항 등의 영향을 고려하였다.

\section{2 조류 및 바람 속도 프로파일}

풍동 시험에서는 실제 구조물이 경험하는 조건과 유사한 환 경 하중을 구현하여 모형선에 걸리는 하중을 계측한다. 따라서 조류 및 바람 속도 분포를 실제와 유사하게 재현하는 것이 필 요하다.

조류는 수선면 아래로 일정 속도를 가지도록 구현하는 것이 바람직하나 풍동 바닥의 마찰로 인해 속도 구배가 발생하였다. 바닥 마찰에 의한 속도 구배 발생을 최소화하는 기법이 Hwang et al.(2016)에 의해 검토되었으나 본 연구에서는 ESDU에서 제 시한 보정법을 이용하여 보정하였다(ESDU 80003, 1986). ESDU 80003 에서 제시한 속도 차이에 의한 하중 계수 보정법은 대상 구조물의 높이 방향으로의 속도 제곱에 비례하여 하중 계수가 영향을 받는 점을 이용한다. 조류하중의 경우에 대상 높이는 각 선박의 흘수에 해당한다. 종방향 힘 $(F x)$, 횡방향 힘 $(F y)$, 및 회두 모멘트 $(M z)$ 성분은 식 (1), 횡경사 모멘트(Mx) 성분은 식 (2)를 통해 풍동 시험 시 계측된 속도 분포를 바탕으로 실제 선박의 조류 속도 조건에 해당하는 하중 계수로 보정한다. 본 실험에서 적용한 하중 계수 보정값은 Table 2에 정리하였다.

$$
C_{\text {corrected }}=\frac{\int_{0}^{T} U_{\text {target }}^{2}(Z) d z}{\int_{0}^{T} U_{\text {actual }}^{2}(Z) d z} C_{\text {measured }}
$$




$$
C_{\text {corrected }}=\frac{\int_{0}^{T} U_{\text {target }}^{2}(Z) \times Z d z}{\int_{0}^{T} U_{\text {actual }}^{2}(Z) \times Z d z} C_{\text {measured }}
$$

Table 2 Current profile correction factors for measured force and moment coefficients

\begin{tabular}{ccc}
\hline \hline Condition & Force Coefficients & Moment Coefficients \\
\hline FLBT & 1.075 & 1.025 \\
170k LNGC & 1.086 & 1.031 \\
30k Shuttle & 1.197 & 1.128 \\
5k Shuttle & 1.224 & 1.155 \\
\hline
\end{tabular}

바람은 해상에서의 바람 속도 분포를 구현하였다. 일반적으로 해상에서의 바람 속도 분포는 다음 식을 통해 구할 수 있다.

$$
U(H)=U\left(H_{g}\right) \times\left(\frac{H}{H_{g}}\right)^{\alpha}
$$

$H$ 는 수선면 상부로부터의 높이를 의미하며 $U(H)$ 는 높이 $H$ 에서의 평균 속도이다. $H_{g}$ 는 기준 높이이며 $U\left(H_{g}\right)$ 는 기준 높이 에서의 평균 속도를 나타낸다. 바람 속도 구배는 $\alpha$ 값을 통해 정해지는데 일반적으로 $1 / 7 \sim 1 / 10$ 범위의 값을 사용한다. 해상에 설치되는 해양구조물에 작용하는 바람은 바람의 진행을 저해하 는 요소가 적기 때문에 높이가 높아짐에 따라 속도 구배가 크 게 발생하다. 본 연구에서는 $\alpha$ 값으로 $1 / 7$ 을 사용하였다.

Fig. 4와 Fig. 5는 풍동 시험에 사용된 조류 및 바람의 속도 구 배이다.

풍동 시험 결과의 정확도는 풍동 시험 영역(Wind tunnel test section) 크기 및 모형 크기 등의 영향을 받으며 이를 폐색 효과 (Blockage effect)라고 한다. 실제 환경에서는 작용하는 바람이 폭 방향으로 균일한 반면 풍동 시험에서는 풍동(Wind tunnel)의 벽면 등에 의해 바람장이 영향을 받는다. 일반적으로 모형의 단

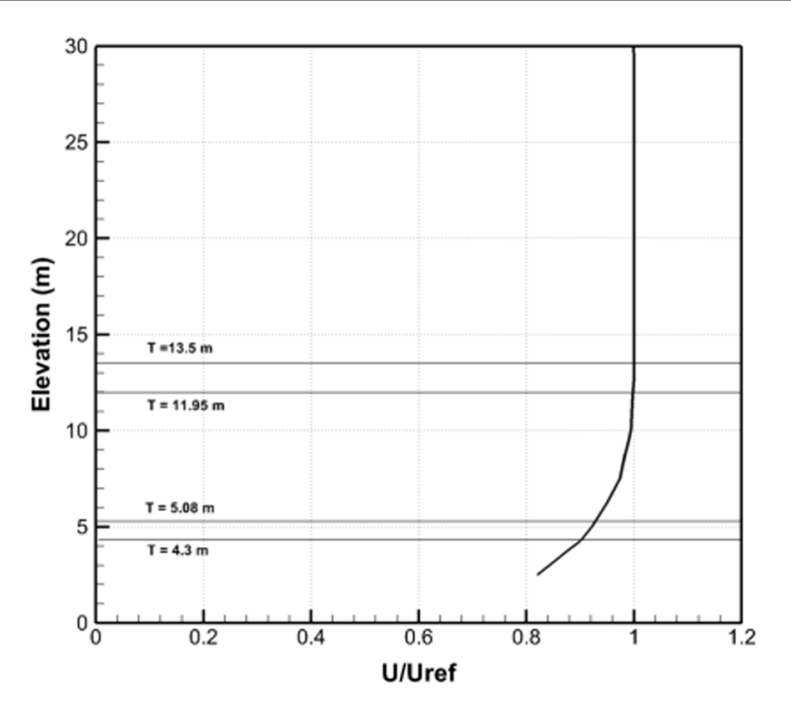

Fig. 4 Current velocity profile for wind tunnel test

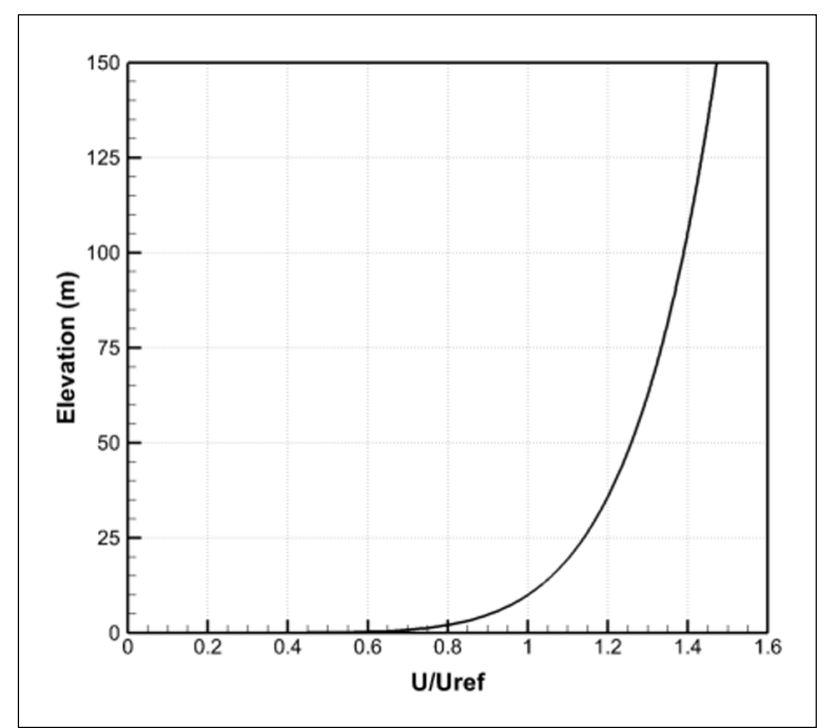

Fig. 5 Wind velocity profile for wind tunnel test

Table 3 Blockage correction factors for FLBT (head wind condition)

\begin{tabular}{cccc}
\hline \hline \multicolumn{2}{c}{ Condition } & $\mathrm{m}$ & $\begin{array}{c}\text { Correction factor } \\
\left(1-m \times \frac{S}{A}\right)\end{array}$ \\
\hline FLBT Alone & Wind & 2.68 & 0.980 \\
FLBT Alone & Current & 1.97 & 0.994 \\
FLBT $+170 \mathrm{k}$ & Wind & 2.71 & 0.968 \\
FLBT $+170 \mathrm{k}$ & Current & 1.96 & 0.991 \\
\hline
\end{tabular}

면적이 풍동 시험 영역(Wind tunnel test section)의 면적대비 $5 \%$ 이하로 유지하는 것이 바람직하며 풍동 시험 결과를 정리함에 있어 폐색 효과(Blockage effect)를 고려하여야 한다. ESDU 80024(1998)는 폐색 면적 비(Blockage area ratio)가 1보다 큰 실 험의 경우, 아래와 같이 보정법을 제시하고 있다.

$$
\frac{C_{F, C}}{C_{F, M}}=1-m \times \frac{S}{A}
$$

$S$ 는 모델의 투영단면적이며 $A$ 는 풍동의 단면적(Cross section area)이다. $m$ 은 반류 확장 계수(Wake expansion factor)로 박리된 기포의 최대 단면적 대비 물체의 기준 단면적 비율을 나타낸 다.(ESDU 80024, 1998). 본 연구에서 사용된 일부 폐색 보정 계 수(Blockage correction factor)를 Table 3 에 정리하였다.

\section{3. 풍동 시험 결과}

\section{1 무차원 계수 및 좌표계}

풍동 시험은 $F x, F y$ 의 2축 힘과 $M x, M z$ 의 2축 모멘트를 계측 하였고 식 (5)-(8)의 무차원 식을 이용하여 하중 계수를 구하였 다. 무차원 식에 사용된 각 선박별 길이 및 면적 정보는 Table 4 와 Table 5에 정리하였다. $A W$ 는 수선면 상부, $U W$ 는 수선면 하 부를 나타내며 $A_{f}$ 는 전면 투영 면적(Frontal area), $A_{s}$ 는 측면 투영 면적(Side area)을 의미한다. $H_{s}$ 는 측면에서의 면적 중심을 
Table 4 Normalizing factors of force and moment coefficients for FLBT and 170k LNGC

\begin{tabular}{ccccc}
\hline \hline & \multicolumn{2}{c}{ FLBT } & \multicolumn{2}{c}{$170 \mathrm{k}$ LNGC } \\
\cline { 2 - 6 } & $A W$ & & $A W$ & \multicolumn{2}{c}{$A W$} & $U W$ \\
\hline$L_{b p}[\mathrm{~m}]$ & \multicolumn{2}{c}{326.0} & \multicolumn{2}{c}{282.2} \\
$L_{\text {oa }}[\mathrm{m}]$ & \multicolumn{2}{c}{355.0} & \multicolumn{2}{c}{294.0} \\
$B[\mathrm{~m}]$ & \multicolumn{2}{c}{60.0} & \multicolumn{2}{c}{45.5} \\
$T[\mathrm{~m}]$ & \multicolumn{2}{c}{13.5} & \multicolumn{2}{c}{12.0} \\
$A_{f}\left[\mathrm{~m}^{2}\right]$ & 2146.0 & 825.0 & 1353.0 & 541.0 \\
$A_{s}\left[\mathrm{~m}^{2}\right]$ & 10101.0 & 4307.0 & 6390.0 & 3309.0 \\
$H_{s}[\mathrm{~m}]$ & 17.6 & 6.9 & 12.0 & 5.9 \\
\hline
\end{tabular}

Table 5 Normalizing factors of force and moment coefficients for $30 \mathrm{k}$ shuttle and $5 \mathrm{k}$ shuttle

\begin{tabular}{|c|c|c|c|c|}
\hline & \multicolumn{2}{|c|}{ 30k Shuttle } & \multicolumn{2}{|c|}{ 5k Shuttle } \\
\hline & $A W$ & $U W$ & $A W$ & $U W$ \\
\hline$L_{b p}[\mathrm{~m}]$ & \multicolumn{2}{|c|}{162.0} & \multicolumn{2}{|c|}{91.2} \\
\hline$L_{o a}[\mathrm{~m}]$ & \multicolumn{2}{|c|}{172.0} & \multicolumn{2}{|c|}{99.0} \\
\hline$B[\mathrm{~m}]$ & \multicolumn{2}{|c|}{26.5} & \multicolumn{2}{|c|}{17.0} \\
\hline$T[\mathrm{~m}]$ & \multicolumn{2}{|c|}{5.1} & \multicolumn{2}{|c|}{4.3} \\
\hline$A_{f}\left[\mathrm{~m}^{2}\right]$ & 648.0 & 133.0 & 288.0 & 73.0 \\
\hline$A_{s}\left[\mathrm{~m}^{2}\right]$ & 2865.0 & 804.0 & 1093.0 & 388.0 \\
\hline$H_{s}[\mathrm{~m}]$ & 9.5 & 2.5 & 9.1 & 2.1 \\
\hline
\end{tabular}

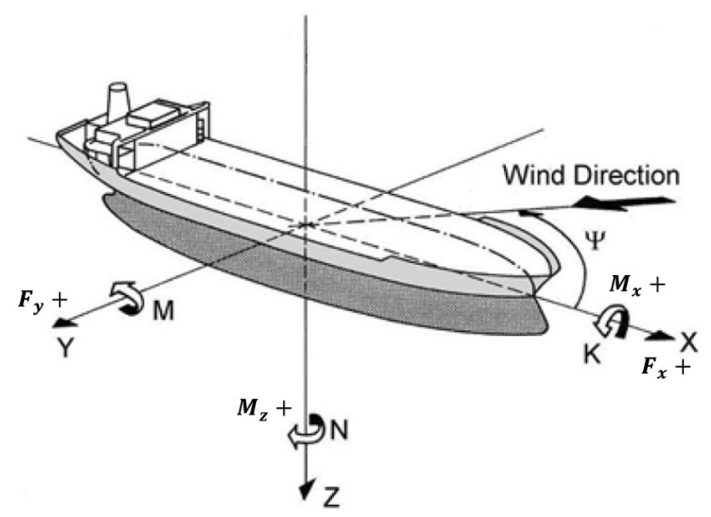

Fig. 6 Coordinate system

나타낸다. 풍동 시험 결과는 Fig. 6에 따라 정의된 좌표계를 이 용하여 나타내었다.

$$
\begin{aligned}
& C_{x}=\frac{X}{1 / 2 \rho U^{2} A_{f}} \\
& C_{y}=\frac{Y}{1 / 2 \rho U^{2} A_{s}} \\
& C_{k}=\frac{K}{1 / 2 \rho U^{2} A_{s} H_{s}}
\end{aligned}
$$

$$
C_{N}=\frac{N}{1 / 2 \rho U^{2} A_{s} L_{o a}}
$$

\section{2 조류하중}

운영 조건에 따라 LNG-BS가 FLBT 주위에 다양한 형태로 배 치되는데, 본 연구에서는 FLBT 단독, FLBT $+170 \mathrm{k}, \mathrm{FLBT}+5 \mathrm{k}$, $\mathrm{FLBT}+30 \mathrm{k}+5 \mathrm{k}$ 의 경우에 대해 풍동 시험을 수행하였다. FLBT 단 독 및 LNG-BS이 병렬 계류 형태로 배치되어 있을 때의 조류하 중 계수 결과는 Fig. 7-10과 같다.

FLBT 및 LNG-BS의 배치는 Fig. 1에서 나타낸바와 같이 FLBT 의 좌, 우현에 각각 위치하도록 설계되어 있다. 따라서 LNG-BS 가 병렬로 배치되었을 경우, 조류 입사각에 따라 조류가 다가오 는 방향에 LNG-BS가 놓이는 형태가 되며 FLBT에 작용하는 조류 에 의한 하중이 영향을 받게 된다. 이러한 영향을 차폐효과 (Shielding effect)라 부르며 일반적으로 상류에 놓은 구조물이 크 면 그 영향도 크다.

조류하중 풍동 시험에서도 이러한 경향을 잘 나타나고 있음 을 확인할 수 있다. 차폐효과의 영향은 종방향 힘보다 횡방향 힘에 크게 작용한다. 이는 FLBT 및 LNG-BS가 병렬 계류로 배 치되어 있으며 일반적인 해양 구조물 및 선박이 길이가 긴 형 태를 가지고 있기 때문이다. 특히, 0 180도 입사각도에서 상대

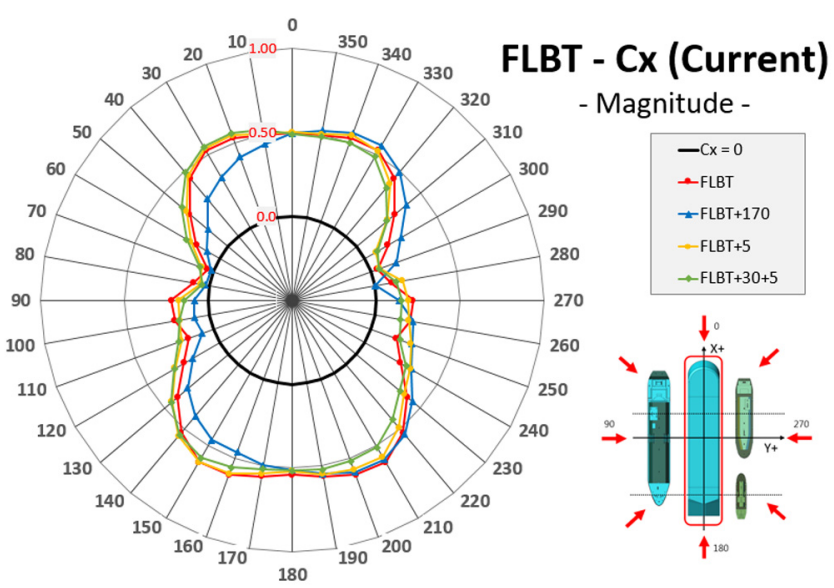

Fig. 7 Current load coefficient of FLBT - $C x$

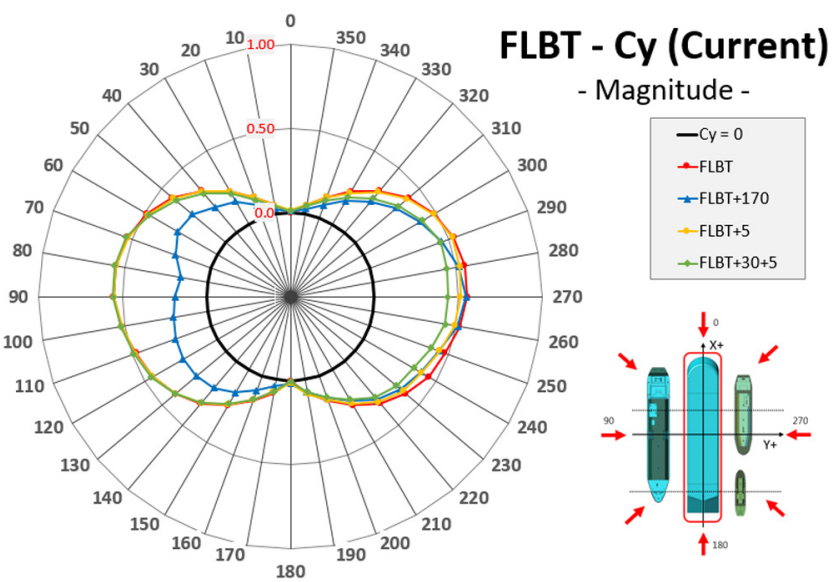

Fig. 8 Current load coefficient of FLBT $-C y$ 


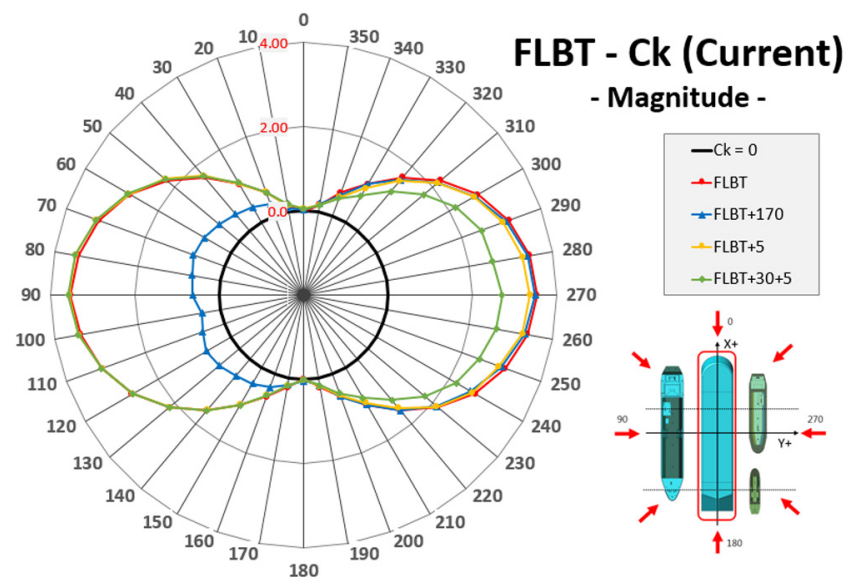

Fig. 9 Current load coefficient of FLBT - $C k$

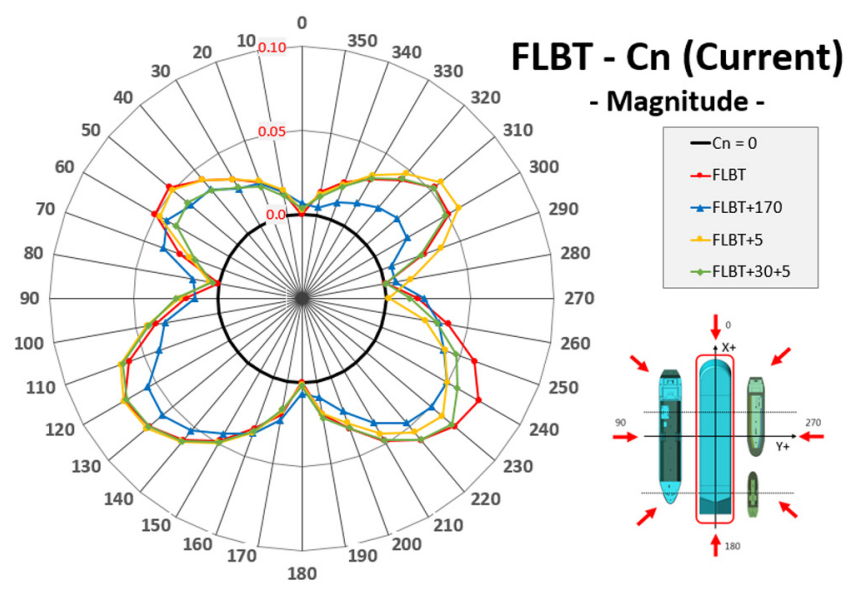

Fig. 10 Current load coefficient of FLBT - $C n$

적으로 크기가 큰 $170 \mathrm{k} \mathrm{LNGC}$ 의 의한 차폐효과가 두드러지게 나타나고 있다. 입사각 90도 기준으로 FLBT 단독 대비 횡방향 힘 $(C y)$ 은 약 $66 \%$, 횡경사 모멘트 $(C k)$ 는 약 $82 \%$ 의 감소를 나타 낸다. 이에 반해 종방향 힘 $(C x)$ 과 회두모멘트 $(C n)$ 는 상대적으로 영향이 작게 나타나고 있다.

180 360도 입사각에 놓인 $30 \mathrm{k}-\mathrm{BS}$ 와 $5 \mathrm{k}-\mathrm{BS}$ 에 의한 힘과 모멘 트의 감소폭은 $170 \mathrm{k} \mathrm{LNGC}$ 에 의한 감소폭에 비해 상대적으로 작음을 확인할 수 있다. 하지만, 회두모멘트 $(M z)$ 의 경우에는 FLBT 단독에 비해 커지는 현상이 발생하였다.

\section{3 풍하중}

FLBT에 작용하는 바람에 의한 힘은 바람에 의해 수선면 상부 에 작용하는 힘으로 풍하중 계수는 조류하중의 식 (4)에서 (7)까 지의 무차원 계수 식과 동일하게 표현된다. 다만, 식에서 각 변수 는 공기의 밀도, 바람 속도, 수선면 상부의 면적을 이용한다.

풍하중 시험은 FLBT 단독, FLBT+170k, FLBT+30k, FLBT+5k, $\mathrm{FLBT}+30 \mathrm{k}+5 \mathrm{k}, \mathrm{FLBT}+170 \mathrm{k}+30 \mathrm{k}+5 \mathrm{k}$ 의 경우에 대해 수행하였다. FLBT 단독 및 LNG-BS이 병렬 계류 형태로 배치되어 있을 때 의 풍하중 계수 결과는 Fig. 11-14와 같다. 차폐효과(Shieling Effect)는 일반적으로 상류에 놓은 구조물이 크면 그 영향도 크 다. 따라서 데크 위에 각종 장비 및 거주구(Accommodation)등이
존재하는 수선면 상부의 풍하중 계측 시 이러한 차폐효과가 조 류하중 대비 크게 나타날 가능성이 높다. 풍하중 풍동 시험에서 도 이러한 영향이 잘 나타나고 있음을 확인할 수 있다. 조류하 중 시험 결과에서 살펴본 바와 같이 차폐효과의 영향은 종방향 힘 성분 보다 횡방향 힘 성분에 크게 작용한다. $0 \sim 180$ 도 입사각 도에서 상대적으로 크기가 큰 $170 \mathrm{k} \mathrm{LNGC}$ 의 의한 차폐효과가 두드러지게 나타나고 있다. 이는 입사각 90도 기준으로 FLBT 단독 대비 횡방향 힘 $(C y)$ 은 약 $72 \%$, 횡경사 모멘트 $(C k)$ 는 약 $53 \%$ 의 감소를 나타내고 있다. 이에 반해 종방향 힘 $(C x)$ 과 회두 모멘트 $(\mathrm{Cn})$ 는 상대적으로 영향이 작기는 하나 상부구조가 복잡 하기 때문에 조류하중에 비해서는 차폐효과가 큰 것을 확인할 수 있다.

180 360도 입사각에 놓은 $30 \mathrm{k}-\mathrm{BS}$ 와 $5 \mathrm{k}-\mathrm{BS}$ 에 의한 힘과 모멘 트의 감소폭은 $170 \mathrm{k} \mathrm{LNGC}$ 에 의한 감소폭에 비해 상대적으로 작음을 확인할 수 있다. 하지만 조류하중을 받는 수선면 하부 대비 풍하중을 받는 수선면 상부의 구조가 복잡하기 때문에서 차폐효과가 크게 나타난다. 입사각 270 도 기준으로 FLBT 단독 대비 횡방향 힘 $(C y)$ 은 약 $40 \%$, 횡경사 모멘트 $(C x)$ 는 약 $22 \%$ 의 감소를 나타내고 있다.

회두모멘트 $(\mathrm{Cn})$ 의 경우에는 FLBT 단독에 비해 FLBT+30k, 입 사각 250 도 조건에서 약 $57 \%$ 증가하여 과도하게 커지는 현상이

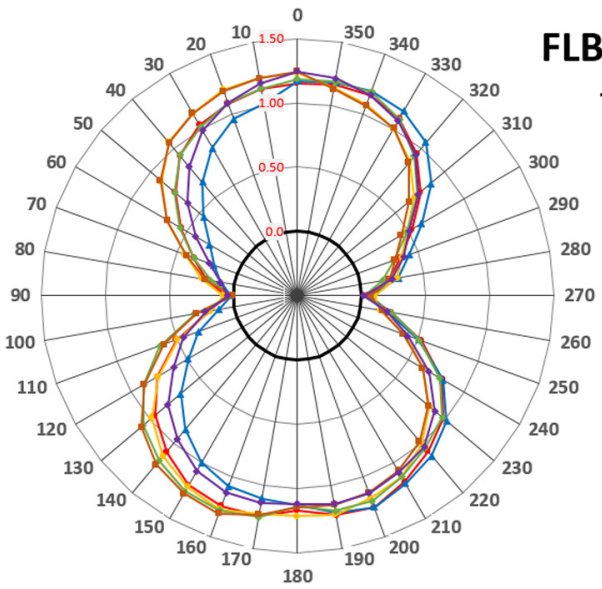

FLBT - Cx (Wind)

- Magnitude $-C \mathrm{C}=0$ $\rightarrow$ FLBT 4 -FLBT+170 $\rightarrow$ FLBT+5 $\rightarrow-F L B T+5$ $-\mathrm{FLBT}+170+30+5$

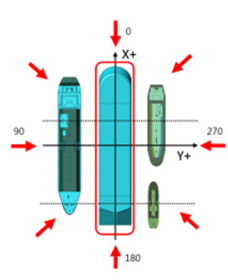

Fig. 11 Wind Load Coefficient of FLBT - $C x$

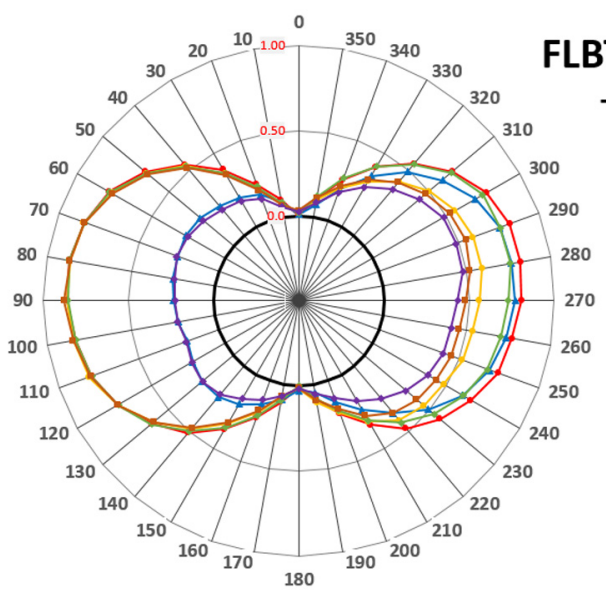

FLBT - Cy (Wind) - Magnitude -

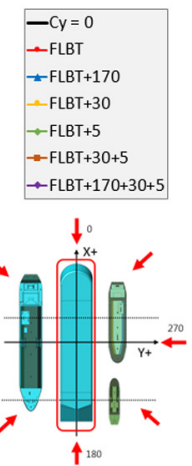

Fig. 12 Wind Load Coefficient of FLBT $-C y$ 


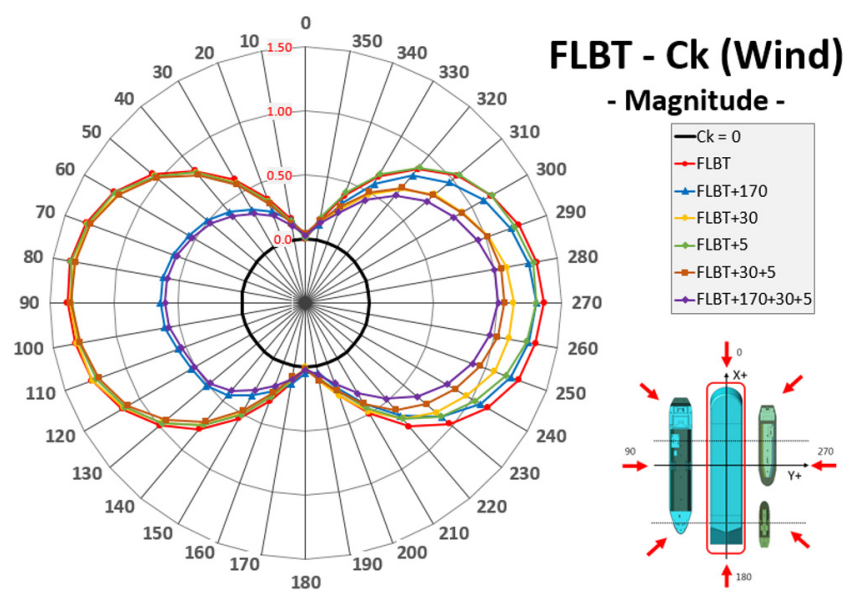

Fig. 13 Wind Load Coefficient of FLBT - $C k$
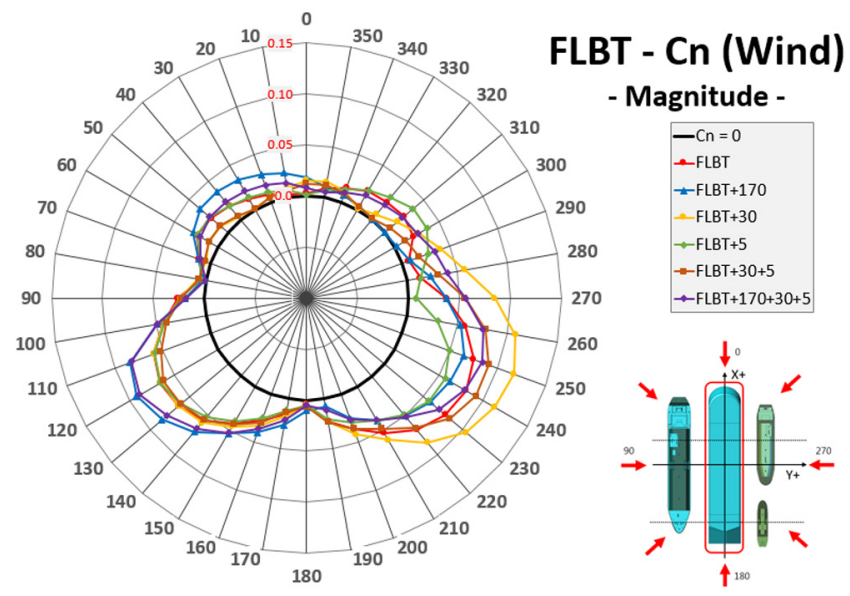

Fig. 14 Wind Load Coefficient of FLBT - Cn

발생하였다. 이는 FLBT 측면에 배치되는 선박의 크기와 상대적 위치에 의한 것으로 FLBT에 작용하는 하중이 FLBT 회전 중심 기준으로 차폐에 의해 불균형이 발생하기 때문이다. 따라서 FLBT와 상대적으로 크기가 작은 선박이 종방향으로 일정한 거 리를 가지며 병렬 배치되는 경우에는 과도한 선수 동요에 의한 충돌에 주의할 필요가 있다.

\section{4. 풍하중 계수 추정}

\section{1 차폐효과를 고려한 추정식}

병렬 계류 상태에서 바람이 불어오는 상류에 위치한 부유체 에 의해 바람이 교란되며 이로 인해 하류에 위치한 부유체는 단독 상태 대비 하중의 크기 및 영향이 달라질 수 있다. 이러한 영향은 풍동 시험 결과인 3.2절 및 3.3절에서 확인하였다.

Fujiwara et al.(2012)는 다양한 조건에서 병렬 계류 부유체에 작용하는 풍하중을 풍동 시험을 통해 계측하였고, 각 작용 방향 별로 힘 성분을 분리하여 풍하중 계수를 추정하는 경험식을 식 (9)부터 식 (12)의 형태로 제시하였다. Fig. 15는 병렬 계류 부유 체의 좌표계를 나타낸 것으로 부유체 사이의 거리 $L_{G A}$ 와 상류 에 놓은 부유체로 인해 하류에 놓은 부유체에 작용하는 바람이 차폐되는 영역의 길이 $L_{S A}$ 가 정의된다.

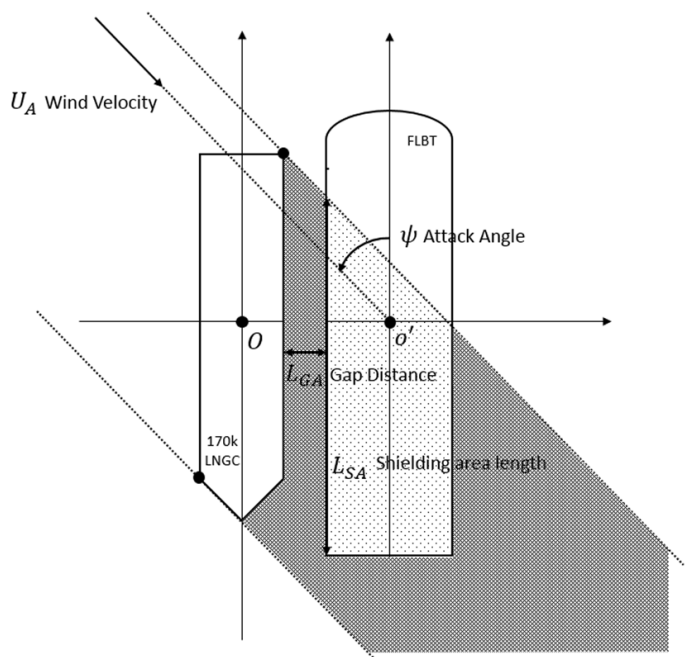

Fig. 15 Coordinate system of wind force coefficients and basic positioning relation between FLBT and 170k LNGC

$$
\begin{aligned}
& C_{x}(\psi)=\left(1-a_{1} C_{S 1} C_{S 2}\right)\left(F_{L F}+F_{X L I}^{\prime}+F_{A L F}\right) \\
& C_{y}(\psi)=\left(1-C_{S 3} C_{S 4}\right)\left(F_{C R}^{\prime}+F_{Y L I}^{\prime}\right) \\
& C_{k}(\psi)=C_{y}(\psi) \times L_{k}(\psi) \\
& C_{n}(\psi)=C_{y}(\psi) \times L_{n}(\psi)
\end{aligned}
$$

식 (9)에서 $a_{1}$ 는 약 0.69 의 값을 가지며 $C_{S 1}$ 과 $C_{S 2}$ 는 각각 부유 체 사이의 거리 $L_{G A}$ 및 차폐되는 영역의 길이 $L_{S A}$ 에 의한 효과 를 고려하는 계수이다. $C_{S 1}$ 과 $C_{S 2}$ 는 실험 결과를 바탕으로 추정 한 값으로 $C_{S 1}$ 은 $L_{G A} / L_{O A}$ 의 변화에 따른 풍하중 계수가 가우시 안 분포 방정식 형태로 표현되며 $C_{S 2}$ 은 $L_{S A} / L_{O A}$ 의 변화에 따른 풍하중 계수가 4차 방정식 형태로 표시된다고 가정하여 정한다. $F_{L F}$ 는 종방향 항력 성분(Longitudinal flow drag component), $F_{X L I}^{\prime}$ 는 종방향 양력 및 유기항력 성분(Longitudinal lift and induced drag component), $F_{A L F}$ 는 3 차원 유동 흐름에 의한 추가 힘 성분을 나타낸다. 식 (10)의 $C_{S 3}$ 과 $C_{S 4}$ 은 각각 식 (9)의 $C_{S 1}$ 과 $C_{S 2}$ 과 동일한 형태로 표현되나 차폐 영향의 차이를 고려하여 식 의 계수 값이 다르게 적용된다. $F_{C R}$ 는 교차항력 성분(Cross flow drag component), $F_{Y L I}^{\prime}$ 는 횡방향 양력 및 유기항력 성분(Lateral lift and induced drag component) 성분을 나타낸다. 식 (11)과 식 (12)의 $L_{k}(\psi)$ 과 $L_{n}(\psi)$ 은 각각 차폐 효과를 고려한 모멘트 레버 를 나타낸다. 대표적인 입사각에 따른 각 계수 및 힘 성분의 값 을 정리하여 Table 6에 정리하였다.

FLBT 단독 조건에서 경험식을 통해 추정한 풍하중 계수와 풍 동 시험의 결과를 Fig. 16-19에 비교하였으며 $170 \mathrm{k} \mathrm{LNGC가} \mathrm{병}$ 렬로 계류된 상태에서 FLBT에 작용하는 풍하중 계수 결과를 Fig. 20-23에 나타내었다.

단독 모델과 $170 \mathrm{k} \mathrm{LNGC}$ 에 의해 차폐되는 병렬 계류 모델 모 두 경험식을 통한 풍하중 계수 추정 결과가 종방향의 풍하중 계수 $C x$ 를 제외하고 대체로 풍동 시험 결과와 잘 일치하는 것 을 확인하였다. 
병렬 계류된 상태에서 FLBT에 작용하는 풍하중은 풍동시험 및 경험식 결과 모두에서 바람이 불어오는 전단에 놓은 $170 \mathrm{k}$ $\mathrm{LNGC}$ 에 의해 상당부분 감소하는 것을 나타났다. 특히, 바람의 입사각이 90 도 부근에서 하중 감소가 크게 발생하였다. 경험 식 을 통해 추정된 횡방향 힘 및 횡방향 모멘트는 90 도 입사각 기

Table 6 Coefficients for shielding effects on wind forces and components of force in longitudinal, lateral, heel and yaw

\begin{tabular}{|c|c|c|c|c|c|}
\hline & & \multicolumn{4}{|c|}{$\operatorname{Attack} \operatorname{angle}(\psi)$ [deg] } \\
\hline & & 0 & 30 & 60 & 90 \\
\hline \multirow{6}{*}{$\begin{array}{l}\text { Longitudi } \\
\text { nal }\end{array}$} & $a_{1}$ & \multicolumn{4}{|c|}{0.690} \\
\hline & $C_{S 1}$ & \multicolumn{4}{|c|}{0.998} \\
\hline & $C_{S 2}$ & 0.000 & 0.639 & 0.658 & 0.467 \\
\hline & $F_{L F}^{\prime}$ & -0.684 & -0.593 & -0.342 & 0.000 \\
\hline & $F_{X L I}^{\prime}$ & 0.000 & 0.091 & 0.221 & 0.000 \\
\hline & $F_{A L F}^{\prime}$ & 0.000 & -0.108 & -0.036 & 0.000 \\
\hline \multirow{4}{*}{ Lateral } & $C_{S 3}$ & \multicolumn{4}{|c|}{1.000} \\
\hline & $C_{S 4}$ & 0.000 & 0.639 & 0.658 & 0.467 \\
\hline & $F_{C R}^{\prime}$ & 0.000 & 0.204 & 0.612 & 0.816 \\
\hline & $F_{Y L I}^{\prime}$ & 0.000 & 0.297 & 0.209 & 0.000 \\
\hline Heel & $L_{k}$ & \multicolumn{4}{|c|}{0.816} \\
\hline Yaw & $L_{n}$ & 0.110 & 0.197 & 0.198 & 0.000 \\
\hline
\end{tabular}

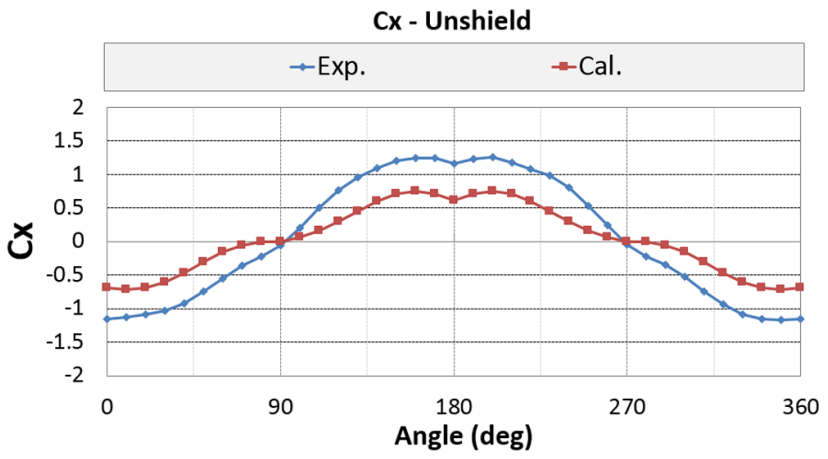

Fig. 16 Comparison of wind load coefficient between wind tunnel test and calculation for FLBT $-C x$ (unshield)

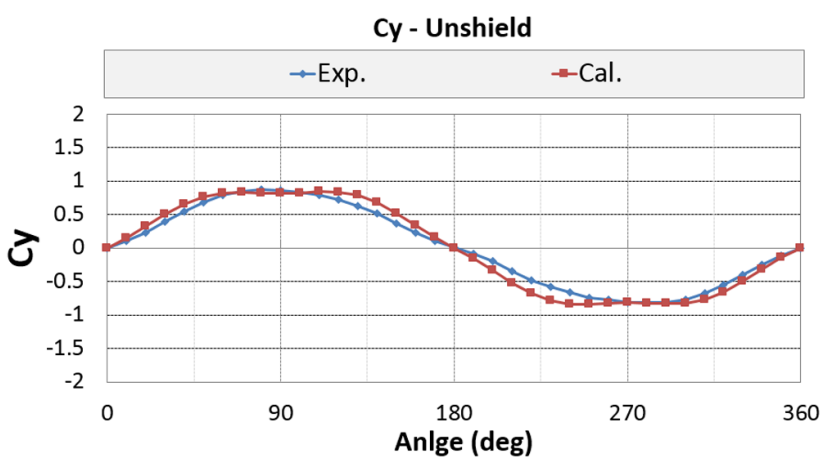

Fig. 17 Comparison of wind load coefficient between wind tunnel test and calculation for FLBT - Cy (unshield)

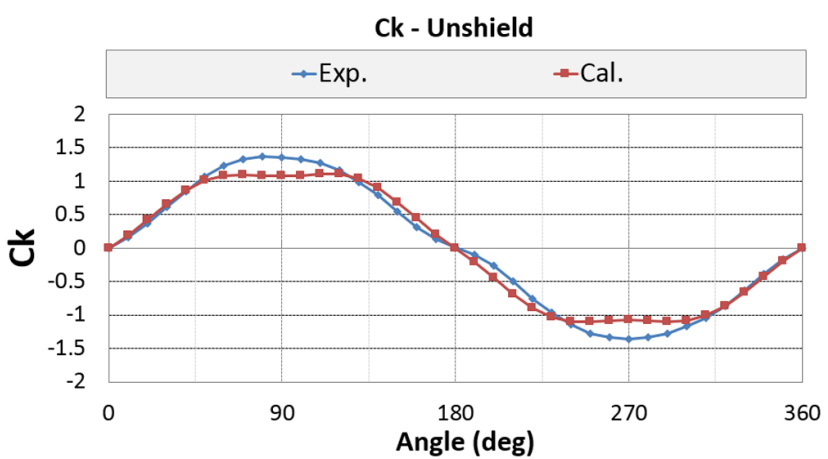

Fig. 18 Comparison of wind load coefficient between wind tunnel test and calculation for FLBT $-C k$ (unshield)

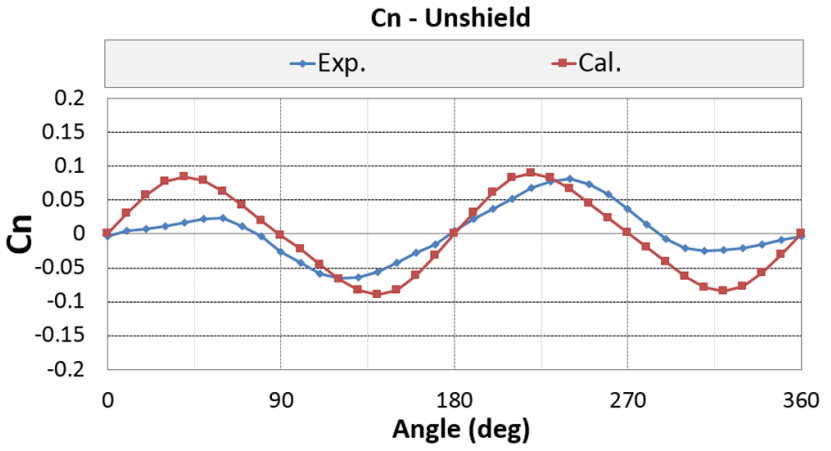

Fig. 19 Comparison of wind load coefficient between wind tunnel test and calculation for FLBT - $\mathrm{Cn}$ (unshield)

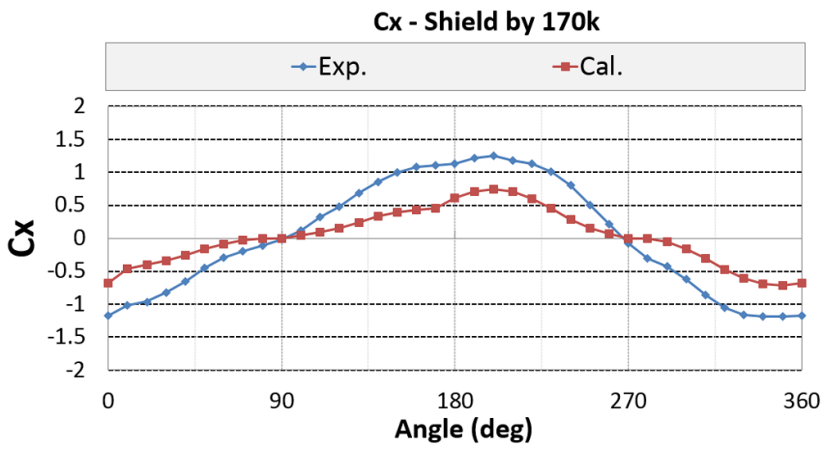

Fig. 20 Comparison of wind load coefficient between wind tunnel test and calculation for FLBT $-C x$ (shield by 170k)

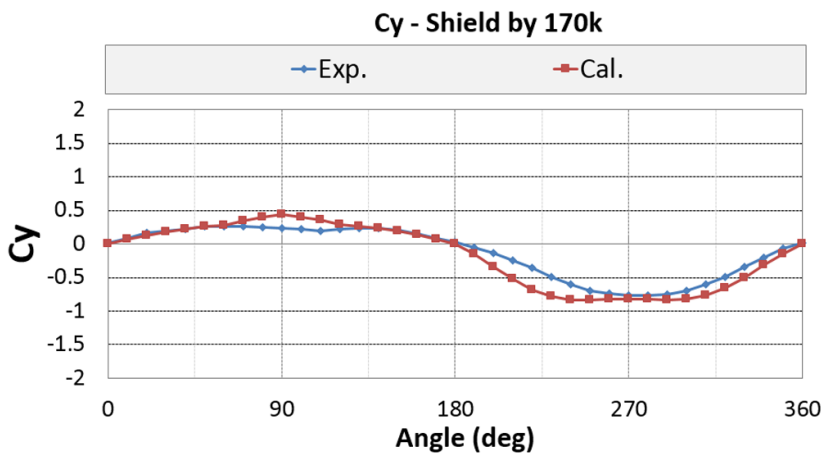

Fig. 21 Comparison of wind load coefficient between wind tunnel test and calculation for FLBT - $C y$ (shield by 170k) 


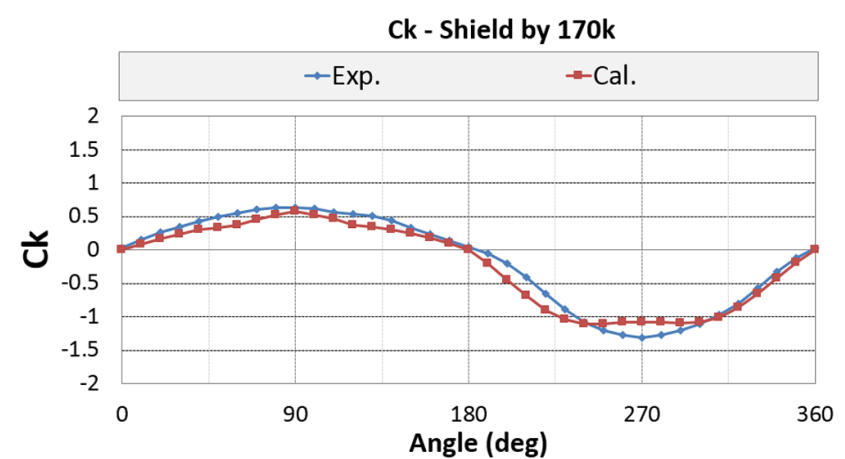

Fig. 22 Comparison of wind load coefficient between wind tunnel test and calculation for FLBT - $C k$ (shield by 170k)

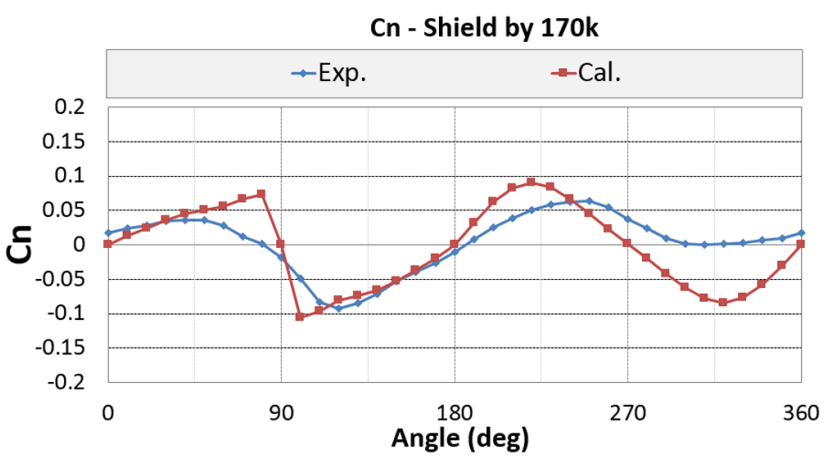

Fig. 23 Comparison of wind load coefficient between wind tunnel test and calculation for FLBT - $C k$ (shield by 170k)

준으로 단독 조건 대비 약 $46 \%$ 감소하며 이 수치는 풍동 시험 에 의한 감소값 $72 \%$ 보다 과소 예측하는 것으로 나타났다. 또한 풍동시험의 종방향 힘과 회두 모멘트는 풍동시험 결과와 다소 차이가 있으나 차폐에 의한 하중 감소 경향을 따라가는 결과를 보여주었다.

종방향으로의 풍하중 계수 차이는 경험식이 $\mathrm{LNGC}$ 의 실험 결 과를 바탕으로 유도되었기 때문에 발생한 것으로 추정된다. 본 연구에서 대상으로 하는 FLBT는 bunkering 등의 작업 등을 위 한 공정 처리 설비(Topside process)가 데크 위에 설치되어 일반 적인 $\mathrm{LNGC}$ 와는 다른 형상을 가지고 있다. 특히, FLBT의 거주 구(Accommodation)와 플레어 타워(Flare tower)가 선수 및 선미 에 각각 위치하기 때문에 종방향으로의 풍하중이 높게 작용하 는 것으로 판단된다.

\section{5. 결 론}

본 연구에서는 $\mathrm{LNGC}$ 및 $\mathrm{LNG-BS}$ 와 병렬 계류된 FLBT에 작 용하는 풍하중 및 조류하중을 추정하기 위해 풍동 시험에서 모 형선을 이용한 실험을 수행하였으며 계측 결과를 바탕으로 하 중 계수를 추정하였다.
단독 FLBT에 작용하는 조류하중 계수와 풍하중 계수를 실험 계측 결과를 바탕으로 추정하였으며 $170 \mathrm{k} \mathrm{LNGC}$ 에 의한 차폐효 과가 횡방향 힘을 크게 감소시키는 것을 확인할 수 있었다. 이 러한 영향은 풍하중 결과에서 상대적으로 크게 나타났다. 회두 모멘트 $(\mathrm{Cn})$ 의 경우에는 조류하중과 풍하중 시험에서 $30 \mathrm{k}-\mathrm{BS}$ 와 $5 \mathrm{k}-\mathrm{BS}$ 가 차폐하는 경우, FLBT 단독에 비해 커지는 현상이 발생 하였다. 따라서, FLBT와 상대적으로 크기가 작은 선박이 길이 방향으로 거리를 가지며 병렬 배치되는 경우 조류 및 바람에 의해 선수 동요가 발생할 가능성이 크다.

풍하중 계수를 경험식을 통해 추정하였고 풍동 시험 결과와 비교하였다. 종방향으로 작용하는 풍하중을 제외하고 추정값과 풍동 시험 결과값이 대체로 일치하는 것을 확인하였다. 종방향 으로의 풍하중 차이는 경험식 유도에 사용된 모형의 형상과 $\mathrm{FLBT}$ 의 형상이 다른 것으로부터 기인한다고 판단되며 정확한 추정을 위해서는 형상 특성을 반영하여 추정식 계수를 적용하 는 것이 필요하다.

\section{후 기}

본 연구는 해양수산부의 국가연구개발사업인 '해상부유식 LNG 벙커링 시스템 기술개발(PMS3730)'의 지원으로 수행된 연 구결과 중 일부임을 밝히며, 연구비 지원에 감사드립니다.

\section{References}

ESDU 80003., 1986. Mean Fluid Forces and Moments on Rectangular Prisms: Surface-mounted Structures in Turbulent Shear Flow. Engineering Sciences Data Unit, London.

ESDU 80024., 1998. Blockage Corrections for Bluff Bodies in Confined Flows. London

Fujiwara, T., Yukawa, K., Sato, H., Otsubo, K., Taniguchi, T., 2012. Wind Effect Estimation in side by side offloading operation for FLNG and LNG carrier ship. OMAE012-83139, Rio de Janeiro, Brazil

Hwang, S.C., Cho, S.K., Jung, H.W., Kim, Y.H., Sung, H.G., Alberto Omar Vazquez-Hernandez, A.O., 2016. An Experimental study of environmental loads acting on a semi-submersible offshore structure, Proceeding of KSOE 2016 Fall in Busan.

Song, C.W., Kim, J., Yoon, S.J., Hong, J.P., Sung, H.G., 2016. Turret Mooring System Design for a Floating Offshore LNG Bunkering Terminal, Proceeding of KSOE 2016 Fall in Busan.

Wnek, A.D., Paco, A., Zhou, X.-Q., Sutulo, S., Guedes Saeres, C., 2015. Experimental Study of Aerodynamic Loads on an LNG Carrier and Floating Platform. Applied Ocean Research, 51, 309-319. 